\title{
Incentives for the key stakeholders in the hybrid use of the UHF broadcasting spectrum utilizing Supplemental Downlink: A dynamic capabilities view
}

\author{
Seppo Yrjölä ${ }^{1}$, Petri Ahokangas ${ }^{2}$, Marja Matinmikko ${ }^{3}$, Pekka Talmola ${ }^{4}$,
}

\begin{abstract}
This paper investigates key stakeholders' incentives for the hybrid use of the Ultra High Frequency (UHF) spectrum for broadcasting and mobile broadband using novel Supplemental Downlink (SDL) Carrier Aggregation (CA) technique from the dynamic capabilities perspective of strategic management. So far broadcaster (BC) community has lacked true incentives for sharing the spectrum they currently use and have seen sharing only as unilateral repurposing act from regulatory bodies and Mobile Network Operators (MNO). In this paper we focus on key stakeholders capability to deal with combined internal and external resources and capabilities in doing business, refered as Dynamic Capability (DC). Spectrum sharing introducing a rapid change in the stakeholders business environments requires dynamic capabilities of hybrid use from both spectrum offering and spectrum utilization perspectives. We focus on identifying and discussing broadcaster incumbents' and MNO licensees' key antecedents, processes, and outcomes related to hybrid use of UHF spectrum using the supplementary downlink (SDL) carrier aggregation (CA) concept. Based on our DC analysis, we found incentives that could motivate both the incumbents and licensees to consider the hybrid use of UHF spectrum as a co-creation opportunity, and provide viewponts for the regulatory bodies to be considered when developing new regulatory models for accessing UHF spectrum.
\end{abstract}

Keywords-Incentives, spectrum sharing, broadcasting, UHF, Supplemenatl Downlink, Carrier Agrregation, 5 G

\section{INTRODUCTION}

Need for the mobile broadband (MBB) is growing at increasing pace [1], placing growing demands on the scarce radio spectrum resources. As increasing percentage of the mobile traffic is video [2] and asymmetry in mobile broadband (MBB) traffic is increasing - average downlink ratio being currently in Europe 8:1. High capacity demand everywhere and the changes in the usage characteristics put mobile broadband service operators against a disruptive change.

At the same time importance of Digital Terrestrial Television (DTT) as the main delivery mechanism of TV content has been disrupted and decreased due to alternative broadband delivery mechanisms and higher spectrum fees for all using the UHF band. Although the users interest in the TV content/programs remains or even increases, the ways how TV

${ }^{1}$ Nokia Networks, Oulu, Finland. seppo.yrjola@nsn.com

${ }^{2}$ Oulu Business School, Oulu, Finland. petri.ahokangas@oulu.fi

${ }^{3}$ VTT Technical Research Centre of Finland, Oulu, Finland.

marja.matinmikko@vtt.fi

${ }^{4}$ Nokia Technologies, Salo, Finland. pekka.hk.talmola@nokia.com content is delivered and received by the user will be and have already been changed. More and more users are getting the TV programs via cable, satellite, fixed broadband and, especially, via Mobile Broadband. Also non-linear usage is increasing as well as the demand for interactivity [3].

With these trends, regulators may gradually withdraw some DTT licenses, one by one, and repurpose these frequencies for MBB use. In addition, the most used DTT licenses can continue as long as required or forever, e.g. free national TV licenses with public service obligations that may be financed by other means than commercial funding. It is assumed that most of DTT will be evolved to Terrestrial Digital Video Broadcasting DVB-T2 technology which is more spectrum efficient than DVB-T and also better supports wide area single frequency networks (SFN).

In addition to repurposing of spectrum, the regulators are increasingly considering new ways of fulfilling the different spectrum demands in the future due to difficulties in finding unused exclusive spectrum and costly and lengthy re-allocation process involved. Spectrum sharing where systems operate in the same spectrum band has lately received growing importance to meet the mobile traffic growth while maintaining the rights of incumbent systems operating in the bands [4]. This rapid change in the business environment especially underlines the role of the broadcaster spectrum holders and opens up new business opportunities as well as risks for the incumbents due to increasing pressure for innovative flexibility in spectrum usage. So far, BC community have lacked true incentives for changing their spectrum use and on the contrary have seen unilateral acts from regulators and MNOs towards further compressing DTT bands to give room for new MBB spectrum: UHF broadcast spectrum was originally from 470 to $862 \mathrm{MHz}, 800 \mathrm{MHz}$ band (790-862) is now been deployed for mobile broadband (MBB) use throughout Europe. World Radiocommunication Conference in 2012 (WRC-12) made a decision on $700 \mathrm{MHz}$ band to be used for MBB after the WRC-15 and FCC in USA has lately made a decision on $600 \mathrm{MHz}$ incentive auctions.

In the recent European spectrum discussions EU set up a High Level Group (HLG) consisting of mobile and broadcast sectors to study the future use of UHF-spectrum and to deliver strategic advice on the future use of the UHF. The European Conference of Postal and Telecommunications Administrations (CEPT) set up Task Group 6 (TG6) "Long term vision for the UHF broadcasting band" [5], to identify 
and analyze possible scenarios for the development of the band taking account technology and service development.

In this paper we focus on analyzing the hybrid usage of the band by DVB and downlink Long Term Evolution (LTE) terrestrial networks. In order to be able to introduce this kind of concept successfully, the broadcaster incumbents need incentives - and not only enforced regulation - for admitting MNO users in the spectrum they are currently occupying.

Although the underlying technical concepts of the SDL and CA are well known and have been already standardized in the 3rd Generation Partnership Project (3GPP) [6], technical hybrid use concept with TV broadcasting has not been validated and there is no work on the business impacts of the concept related to hybrid UHF use, especially from the BC incumbents' perspective. Recent research proposes that the regulatory framework around spectrum sharing represents the most influential force and that, to enhance the success of the concept, the business perspective plays an important role for the incumbent spectrum users [7].

Companies in rapidly changing environment need to anticipate change and to react to it. The ability to do this systematically is referred as Dynamic Capability (DC) [8]. Teece et al. defined DC as a "firm's ability to integrate, build and reconfigure internal and external competences to address rapidly changing environments" [8] which can be described in terms of which actions are taken to adjust a company's resources into new forms of competitive advantage. This paper addresses the following research questions from the DC perspective

- What DCs are required for the key stakeholder systems of hybrid usage of the UHF band using SDL CA?

- What are the incentives of the hybrid use?

- Could this be of help to regulators studying the future use of UHF-spectrum?

The rest of this paper is organized as follows. The following section gives a brief overview of the hybrid usage of the UHF band by DVB and/or downlink LTE terrestrial including SDL CA concept, and the third introduces the theory of DCs including an interpretation of the UHF sharing concept from the DC perspective. The fourth section discusses incentives for the broadcaster incumbents and MNO licensees to share spectrum. Finally, the last section draws the conclusions and suggest future research.

\section{HYBRID USAGE OF THE UHF BAND BY DVB AND/OR DOWNLINK LTE TERRESTRIAL}

\section{A. Hybrid usage of the UHF band}

As a long term vision, the UHF band 470-694 $\mathrm{MHz}$ can accommodate both delivery of TV content as well as additional capacity for MBB. In their vision work TG6 created the following scenarios [5]:

- Class A: Primary usage of the band by existing and future DVB terrestrial networks
- Class B: Hybrid usage of the band by DVB and/or downlink LTE terrestrial networks

- Class C: Hybrid usage of the band by DVB and/or LTE (including uplink) terrestrial networks

- Class D: Usage of the band by future communication technologies

SDL CA introduces a flexible way of how to transfer TV channels to mobile use while maintaining capability to deliver TV content both in conventional living room large screen use cases as well as new mobile use cases on smart phones and tablets.

TV content itself and delivery mechanisms are different matters and need to be separated. Although the users interested in the TV content/programs remains or even increases, the ways how TV content is delivered and received by the user will be and have already been changed. Increasingly users are receiving the TV programs via cable, satellite, fixed broadband and, especially, via MBB. Also non-linear usage is greatly increasing as well as the demand for interactivity.

Recent studies show that the demand and value for DTT as the main delivery mechanism of TV content will decrease [3] Based on that it is further assumed that some 'underutilized' and lower valued TV frequencies can be reassigned and/or shared with mobile use.

As the freed TV channels can be different in different geographical areas, we are proposing to assign them for the MBB downlink use only. SDL use is more compatible, compared with traditional Frequency Division Duplex (FDD) or Time Division Duplex (TDD) use, with the remaining DTT use. FDD operation also requires more harmonized conditions and a wider freed spectrum block at the same time and also TDD includes uplink that is less compatible with the DTT use. The freed TV channels could be taken into mobile use in a flexible way by using functionalities that are already developed for flexible/shared access like e.g. recently widely discussed Licensed Shared Access (LSA) concept [9], allowing different time schedules in different countries and regions, if needed. SDL allows both 'traditional' MBB DL and LTE Evolved Multimedia Broadcast Multicast Service Broadcast (eMBMS) [10] usages in a flexible way based on demand. eMBMS should be seen here more as a cell capacity optimization tool rather than a dedicated broadcast channel. SDL use would also support the trend that the future MBB traffic is asymmetric towards downlink direction.

The change of spectrum use can follow the development of market demand. Potential scenarios for Europe are illustrated in figure 1. The spectrum usage can evolve so that the DTT use could be moved towards the lower end of the 470-694 MHz band, when more spectrum is freed from DTT. When DVB-T2 technology is used the DTT networks could become large SFNs, where possible. It should also be noted that as the SDL base stations are replacing the DTT frequencies one by one locally, there is no change in the availability of interleaved spectrum used for example Program Making and Special Events (PMSE). Depending on a country's situations and market demand it should also be possible to fully migrate to 
LTE using either SDL and/or eMBMS to deliver TV content and hence completely replace current DTT technologies.

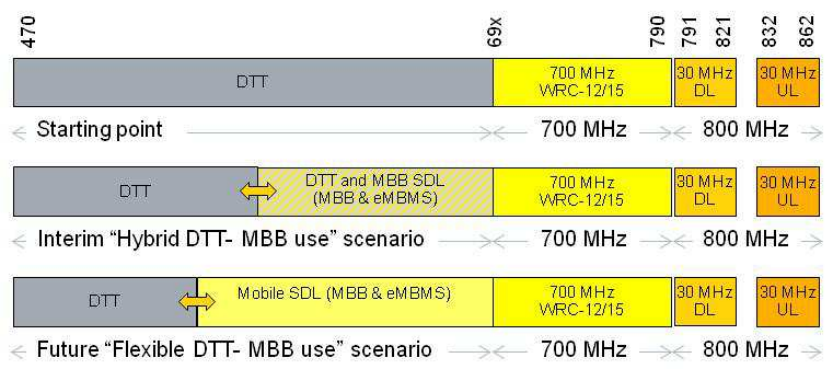

Figure 1. Scenarios for the hybrid usage of the UHF band by DVB and/or downlink LTE terrestrial

\section{B. Supplemental Downlink concept}

As illustrated in Figure 2. SDL uses unpaired spectrum to enhance the downlink capability of MBB networks by enabling significantly faster downloads and supporting a much greater number of users with mobile or portable wireless devices. The technology allows the bonding of the usual downlink with a supplemental downlink channel(s), in a different band, into a single wider downlink channel. Approach has not been used until now in mobile networks due to late availability of required Carrier Aggregation (CA) technology.

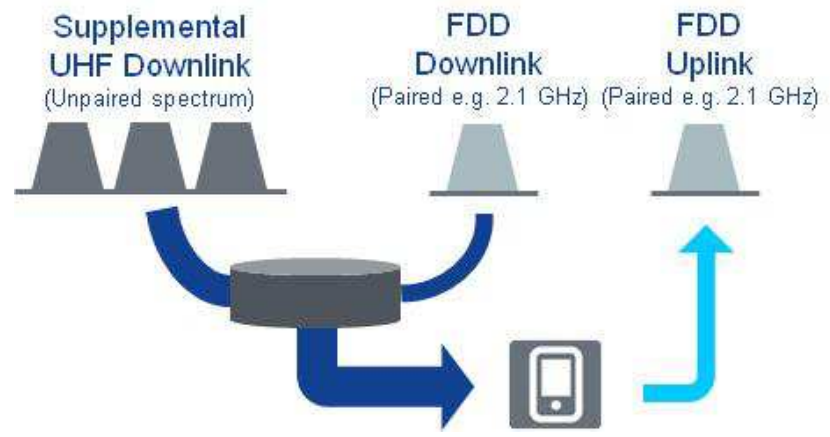

Figure 2. Supplemental Downlink concept

SDL and CA are now enabled in the 3GPP HSPA+ and LTE-A standards. CA across bands is supported in HSPA+ R9 (and beyond) and LTE R10 (and beyond) standards. Each specific bands combination has to be defined in 3GPP.

SDL and CA are moving from concepts to reality. For example L band (1452-1492 MHz) harmonized in Europe [11] and $700 \mathrm{MHz}$ in the US with AT\&T, planned launch 2014.

\section{DYNAMIC CAPABILITIES AND HYBRID USAGE OF THE UHF BAND}

\section{A. Theory of dynamic capabilities}

In order to analyze incentives for the spectrum users in the shared UHF spectrum, it is important to pay attention to the dynamics between the key stakeholders, i.e., the BC incumbents and the MNO licensees. Implementation of hybrid usage of the band by DVB and/or downlink LTE terrestrial networks is based on a strong operational collaborative connection between the incumbent and the licensees, requiring common sharing framework, information sharing and combined technical and business capabilities.

Strategic management literature employs DC framework to analyze the sources and methods of value creation and capture in the environments of rapid technological change. DC approach is focusing on how to be able to systematically create new ways of doing in addition to having the basic capabilities in place. The concept of dynamic capabilities facilitates the identification of company specific capabilities that are critical to company competitive advantage, and abilities to reconfigure resources and routines [8]. In the DC research the concept of dynamic capabilities can be divided into three domains: DC itself (contents and processes), its antecedents (internal and external) and its outcomes in terms of economic performance, competitive advantage and growth [12].

DC research has traditionally emphasized the role of a specific company, but recently the scope has been widened to inter-organizational relationships. For example a company's capability to access and to utilize partners' complementary resources and capabilities as an alternative to developing capabilities themselves or acquiring other organizations' capabilities. Regarding DCs and collaborative contexts, Eriksson [13] pointed out the importance for stakeholders to continuously see the value of the collaborative arrangement and pay attention to monitoring of partner activities. Also, it is important that the concurrent outputs of the partners are compatible and activities possible to be integrated. The DC framework has been applied to mobile communications in [14] to derive incentives for incumbent spectrum uses in the LSA concept. In this paper we expand the work by applying DC to the hybrid usage of the UHF band.

\section{B. Hybrid usage of the UHF band in dynamic capabilities framework}

Based on the scenarios of the hybrid usage of the UHF band utilizing SDL and definition of DCs, we divided the needs for the DCs according to key stakeholder systems considering both spectrum provisioning and its utilization:

- The incumbent broadcasting network - Excess spectrum as the required basic asset that the incumbent controls and inputs the information regarding the availability of spectrum to be shared into spectrum repository.

- Regulatory system - The Regulator sets up the sharing framework involving incumbents and potential licensees and grants a UHF license to a particular licensee (MNO) and runs spectrum repository containing information on available spectrum with agreed conditions and rules for sharing.

- The mobile broadband LTE networks and Operations Support Systems (OSS) - the licensee's radio networks utilizes the spectrum. The Incumbent and the licensee define details of the sharing arrangement and operation. Operator's OSS takes care of the actual control of the spectrum sharing by employing the sharing rules. 
Table I presents a dynamic capabilities framework withdetails by looking at the antecedents, contents and processes, and outcomes for the key stakeholder systems. The starting point for understanding hybrid usage of the UHF band from DCs perspective is the incumbent broadcast network system and the excess spectrum. Due to incumbents' obligations and high investments made in their systems, it is natural that they want to continue to use the spectrum they have access to. As an antecedent for hybrid use, analog to digital TV transition with new TV content consumption habits has led to incumbents' underutilization of spectrum which in many countries was followed by a situation where the regulator is pressured to give a price tag to spectrum. However, there has to be enough spectrum available to be shared. Also, control and appropriateness of value related rules over spectrum have to be clear for the incumbent (as uncertainties would constitute obstacles to hybrid model). Regarding the key processes for spectrum sharing like LSA, the incumbent must be capable for identifying and offering the spectrum for hybrid use and sharing. Based on these antecedents and processes, the outcomes must include good enough interference protection and possibility for additional incentives for the incumbent. Also, incumbents could be able to avoid repurposing by sharing, reach increased efficiency of spectrum use, and earn savings in spectrum fees (if price tags are enforced by regulation). The incumbents could also make additional use for the underutilized spectrum as well as try to enhance collaboration with licensee e.g., through utilizing MBB network as an additional means to deliver the content to increased number of customers and devices.

The second area for DCs in hybrid usage is the regulatory system. As an antecedent we can consider that a standardized spectrum repository, with defined interfaces, must exist and the required level of security must be maintained; moreover, unnecessary complexity has to be avoided, despite the interoperability taking place between the incumbents and licensees. The key processes in this area are related to making the spectrum available for hybrid use and sharing. The Regulator sets up the sharing framework involving incumbents and potential licensees and grants a UHF license to a particular licensee (MNO) and runs spectrum repository containing information on available spectrum with agreed conditions and rules for sharing. In case of multiple repositories, the coordination between repositories is necessary. Finally, tracking spectrum usage could be enabled e.g., to use the data to define license fees or fines imposed to stakeholders due to violations of sharing rules.

The sharing framework, rules and granting the license can be seen as the key to success. As an antecedent we identify supporting legislation and regulators' willingness to go for sharing, therefore selecting the bands, with Quality of Service (QoS) guarantees and long-term availability. On one hand, the MNOs' need for additional spectrum, to be used under fair and transparent access rights, serves as the second essential starting point. On the other hand, governments' aim to drive innovation and enhance competition should support this. For incumbents themselves the degree of information required for sharing and the price tags put to spectrum need to be acceptable. Regarding the key processes, the establishment of a sharing framework between the regulator, incumbent and MNOs - with technical, commercial, and information sharing issues - plays a crucial role. In addition it's important to consider antecedents related to national DTT specific public policy goals like the delivery of commercial Public Service Broadcasting (PSB) and local TV services currently still dependent upon DTT.

As an outcome from the sharing rules, we identify lower entry barriers and flexibility in spectrum use. Also, increased competition, efficiency of spectrum use, and better pricing for spectrum can be seen as the outcomes of sharing. Collaboration with MNOs in content delivery using MBB opens up new business opportunities and potentially widens customer base for both stakeholders.

Thirdly, at the MNO's radio network, as antecedents we identify technology harmonization, emerging and scalable LTE ecosystem, existing market positions of MNOs (dominant, green-field operator), the type of cells utilized (macro/small cell), balancing between demand/current network load and existing spectrum resources. At the MNO's OSS and network management level we identify as an antecedent the understanding of the networks as a whole and novel network optimization tools and methods like Self Organizing Networks $(\mathrm{SON})$. The key processes we see are the planning, configuration and optimization of the network, according to rules and conditions of the sharing framework in order to avoid any harmful interference and to optimize utilization of available spectrum assets.

Based on these antecedents and processes, key outcome for the $\mathrm{MNO}$ is to gain access to valuable spectrum below $1 \mathrm{GHz}$ for improved data coverage, to cope with booming data traffic asymmetry and to fulfill government broadband agendas.

Outcomes must include good enough interference protection and possibility for avoided network costs and/or additional consumer benefit surplus revenue for the incumbent. Also, savings in spectrum fees are possible as non exclusive nature of the asset. In addition to traditional MBB domain benefits MNO licensees could explore new business through using MBB network to deliver part or in the future all the BC content.

\section{INCENTIVES FOR HYBRID USE OF UHF BAND IN DYNAMIC CAPABILITIES' FRAMEWORK}

Building on our analysis, hybrid use of UHF spectrum offers new opportunities to incumbents, regulators and mobile network operators. In the section III we discussed how DCs can be effectively used to take advantage of the new shared use of UHF spectrum. Next we will focus on analyzing the incentives that can plausibly be triggered to exploit the hybrid framework using both the incumbents' and licensees' DCs. In Table II the key incentives are listed. By and large, incumbents and licensee incentives can be seen complementary. However, some of those incentives related to future $\mathrm{MBB}$ eMBMS only business scenario may lead to co-opetitive settings reducing willingness to collaborate without regulatory pressure.

The hybrid shared use option to collect a compensation for spectrum sharing in UHF BC spectrum is a strong direct 
incentive for incumbents' agreement, depending on the national situation. These agreements with MNOs looking for the additional low band spectrum for their operations - could include financial clauses that would enable generating additional revenues. In-kind compensations could be another option between incumbents and licensees, e.g. in the form of utilizing MNO's infrastructure or technology.

TABLE I. HYBRID USE OF THE UHF ABND IN THE DV VIEW

\begin{tabular}{|c|c|c|c|}
\hline & Antecedents & Processes & Outcomes \\
\hline $\begin{array}{l}\text { Incumbent } \\
\text { broadcast } \\
\text { network / } \\
\text { Excess } \\
\text { spectrum }\end{array}$ & $\begin{array}{l}\text { Analog to digital TV transition } \\
\text { and change in consumption habits } \\
\text { Underutilization of spectrum } \\
\text { Pressure from regulator to price } \\
\text { tag the spectrum } \\
\text { Incumbent's and national } \\
\text { common social needs to continue } \\
\text { service provision } \\
\text { Enough spectrum available in } \\
\text { desirable areas and spectrum bands } \\
\text { for long enough time } \\
\text { Clarity over the control and } \\
\text { appropriateness of spectrum }\end{array}$ & $\begin{array}{l}\text { Identifying and offering } \\
\text { spectrum for hybrid use and } \\
\text { sharing. } \\
\text { Utilization of novel spectrum } \\
\text { efficient broadcasting technologies } \\
\text { like DVB-T2 and SFN. } \\
\text { Need to modernize TV content } \\
\text { delivery. }\end{array}$ & $\begin{array}{l}\text { Get additional income, or save } \\
\text { on spectrum fees } \\
\text { Interference protection for } \\
\text { incumbents } \\
\text { Maintain rights to use the band } \\
\text { (no repurposing) } \\
\text { Make additional use for } \\
\text { underutilized spectrum } \\
\text { Collaboration with MNOs in } \\
\text { content delivery } \\
\text { Access more customers and } \\
\text { devices }\end{array}$ \\
\hline $\begin{array}{l}\text { Regulator } \\
\text { Sharing } \\
\text { framework, } \\
\text { licenses and } \\
\text { Spectrum } \\
\text { repository }\end{array}$ & $\begin{array}{l}\text { Supporting legislation and } \\
\text { regulators' willingness to go for } \\
\text { sharing (in selected bands) } \\
\text { MNOs' need for capacity } \\
\text { leading to demand for spectrum } \\
\text { Government finds financial } \\
\text { resources (from spectrum sharing), } \\
\text { drives innovation, requires fair and } \\
\text { transparent granting of access } \\
\text { rights, promotes competition, } \\
\text { information for sharing, use of } \\
\text { price tags to spectrum, guarantees } \\
\text { QoS and long-term spectrum } \\
\text { availability } \\
\text { Standardized repository system } \\
\text { with interfaces } \\
\text { Required security, inter- } \\
\text { operability, controlled degree of } \\
\text { complexity }\end{array}$ & $\begin{array}{l}\text { Establishment of sharing } \\
\text { framework between regulator, } \\
\text { incumbent(s) and MNO(s), } \\
\text { agreement of rules and conditions } \\
\text { concerning technical, commercial } \\
\text { and information sharing related } \\
\text { aspects. } \\
\text { Making spectrum available for } \\
\text { sharing in time, space, frequency } \\
\text { for the licensee(s) and granting } \\
\text { licenses. } \\
\text { Employing rules \& conditions } \\
\text { embedded in repository, with } \\
\text { coordination between databases if } \\
\text { there are many } \\
\text { Tracking or monitoring the use } \\
\text { of spectrum }\end{array}$ & $\begin{array}{l}\text { Lower entry barrier to access } \\
\text { spectrum, flexibility in spectrum } \\
\text { use (for MNO without coverage } \\
\text { obligations) } \\
\text { More competition, and more } \\
\text { efficient use of spectrum use } \\
\text { Better valuation of shared } \\
\text { spectrum (price tag) } \\
\text { Quality of service (QoS) and } \\
\text { guaranteed spectrum use } \\
\text { Preserve social benefits of } \\
\text { DTT while reacting to changed } \\
\text { consumer content consumption } \\
\text { Possibility to monitor and trace } \\
\text { the use of spectrum, possible } \\
\text { harmful interference, and other } \\
\text { phenomena } \\
\text { Possibility to use data for } \\
\text { license fees and possible fines }\end{array}$ \\
\hline $\begin{array}{l}\text { MBB Radio } \\
\text { networks } \\
\text { (radio+core } \\
+ \text { OSS and } \\
\text { network } \\
\text { management) }\end{array}$ & $\begin{array}{l}\text { Harmonization of technology, } \\
\text { scalable LTE ecosystem, market } \\
\text { position of MNO (dominant, green- } \\
\text { field operator), type of cells } \\
\text { (macro/small cell), balance } \\
\text { between demand/current network } \\
\text { load and existing spectrum } \\
\text { resources } \\
\text { Deep insight into network with } \\
\text { novel networks OSS and } \\
\text { management tools to control and } \\
\text { optimize the networks based on } \\
\text { needs, availability and security }\end{array}$ & $\begin{array}{l}\text { Network planning, } \\
\text { configuration and optimization } \\
\text { based on hybrid UHF band } \\
\text { availability, regulatory rules, } \\
\text { sharing framework and existing } \\
\text { network assets. } \\
\text { Novel OSS SON features to } \\
\text { steer the use of hybrid UHF band } \\
\text { as a part of the Heterogeneous } \\
\text { Network (HetNet) based on the } \\
\text { spectrum conditions( calculation of } \\
\text { interferences) e.g through load } \\
\text { balancing and traffic steering } \\
\text { methods. }\end{array}$ & $\begin{array}{l}\text { Access to flexible potentially } \\
\text { lower cost extra capacity, } \\
\text { optimized use across all MNO's } \\
\text { spectrum assets } \\
\text { Ensures the incumbents' } \\
\text { protection from harmful } \\
\text { interference from licensee } \\
\text { Use of spectrum for TV } \\
\text { content delivery for the special } \\
\text { events and BC TV content }\end{array}$ \\
\hline
\end{tabular}

The option for the hybrid use of UHF spectrum for incumbent with possible monetary compensation can be an incentive to validate how well their inputs are combined to provide their social and/or commercial services. Indeed, spectrum is the key asset to provide electronic wireless services and, in the absence of market-based mechanisms, spectrum may not be valued at its opportunity cost. Hybrid shared use involving agreements between parties, also introduces monetary value for the UHF BC spectrum, traditionally only assigned on administrative basis. Incumbents recognizing this opportunity cost might, for instance, consider upgrade their transmission technology to improve efficiency of their 
spectrum use and look for profitable hybrid agreements for the freed channels. In addition to net benefits from compensations technological upgrading to novel higher definition techniques could at the same time introduce customer surplus.

Incumbent incentives, however, are highly dependent on the surrounding conditions, in particular regulatory actions. For instance monetary compensation from freed spectrum could be feed into the national budget, instead of remaining with the incumbent. As national spectrum regulations with budgetary conditions for broadcasting services plays essential role in the concept, one recommendation may be to check and change them - where appropriate - in order to enable BC incumbents to retain any proceeds from sharing framework and agreements. As proposed in the case of LSA sharing concept the common incentive schemes may help to achieve this. [14]

In the case of shared use of DTT spectrum due to limited number of parties, known fixed number of base transmitter sites and low complexity of the system transaction costs will be low.

The growing regulator interest to improve the efficiency of spectrum utilization will act as a strong incentive to push incumbents toward sharing. As lately seen in $800 \mathrm{MHz}$ and $700 \mathrm{MHz}$ bands regulators may decide to further compress incumbents operations and move to lower UHF frequency but this has been and continues to be extremely lengthy and costly process. The hybrid shared use could avoid or adds flexibility for the need for repurposing. Considering the public social role of the broadcaster community, agreements with MNO licensees could offer opportunities to improve their public reputation and image.

As a part of the recent TV White Space (TVWS) regulatory discussion in the USA "use-it-or-lose" clauses have been mentioned as additional regulatory tool to promote efficient use of spectrum. Mandatory hydrid use and sharing, however, is unlikely to be successful, whereas the right incentives with fair mutual agreements will deliver better efficiency and outcomes.

Valuation and fees paid for the $\mathrm{BC}$ and $\mathrm{MBB}$ spectrum have traditionally differed a lot due to national specific social role of the broadcasting industry. In the disrupted media industry with alternative content distribution means situation is changing. From the MBB industry perspective national regulators are already moving toward more liberal spectrum use. The greater the freedom regulators leaves to parties in usage and setting fees, more spectrum will become subject to market prices and further the more compensations may reflect players' willingness to pay for spectrum.

TABLE II. INCENTIVES FOR BROADCAST AND MBB OPERATORS

\begin{tabular}{|c|c|}
\hline \multicolumn{1}{|c|}{ Broadcast incumbent } & MNO licensee \\
\hline $\begin{array}{l}\text { Preserve rights to use the band } \\
\text { instead of repurposing; Use it or } \\
\text { lose it }<\rightarrow>\text { use it or share it }\end{array}$ & $\begin{array}{c}\text { Faster access to QoS licensed } \\
\text { below 1GHz spectrum without } \\
\text { mandatory coverage obligations }\end{array}$ \\
\hline $\begin{array}{l}\text { Additional income } \\
\begin{array}{l}\text { Possibility for in-kind } \\
\text { compensation between an } \\
\text { incumbent and MNO as }\end{array}\end{array}$ & $\begin{array}{l}\text { Possibly lower cost spectrum } \\
\text { when and where needed } \\
\text { To cope with asymmetric } \\
\text { traffic growth. }\end{array}$ \\
\hline
\end{tabular}

\begin{tabular}{|c|c|}
\hline $\begin{array}{l}\text { alternative for monetary } \\
\text { exchanges }\end{array}$ & \\
\hline $\begin{array}{l}\text { The need to save in } \mathrm{BC} \\
\text { spectrum fees due to emerging } \\
\text { regulator pressure towards } \\
\text { market based prices. }\end{array}$ & $\begin{array}{l}\text { Savings in spectrum fees } \\
\text { through collaboration }\end{array}$ \\
\hline $\begin{array}{l}\text { Utilize of LTE ecosystem and } \\
\text { MBB network for content } \\
\text { delivery; Deliver long tail of TV } \\
\text { content }\end{array}$ & $\begin{array}{l}\text { New business opportunity in } \\
\text { delivering BC content using } \\
\text { MBB networks }\end{array}$ \\
\hline $\begin{array}{l}\text { Enhance public image through } \\
\text { improved spectrum efficiency } \\
\text { and enabling new consumption } \\
\text { trends } \\
\text { Gain access to new customers } \\
\text { and more devices }\end{array}$ & $\begin{array}{l}\text { MNOs looking for ubiquitous } \\
\text { customer experience in the } \\
\text { merging media and ICT era. } \\
\text { Opportunity benefits of } \\
\text { booming Over-The-Top (OTT) } \\
\text { traffic }\end{array}$ \\
\hline
\end{tabular}

\section{CONCLUSIONS}

Recent moves to make the $700 \mathrm{MHz}$ band available for MBB have opened up discussions on the future use of the remaining broadcasting spectrum, which is highly attractive for MBB services. Today, the FCC works on concrete plans to allocate $600 \mathrm{MHz}$ band for MBB. In Europe many stakeholders consider the $470-694 \mathrm{MHz}$ spectrum essential for DTT, however the level of dependency on DTT, varies strongly across countries and regions. Cable, satellite and IP TV is taking an increasing share in covering the consumers' needs in stationary "living room" scenarios while conventional DTT has limitations in meeting the surge in demand for more programs at higher resolutions. At the same time, the consumers' behavior is changing; in particular younger people use increasingly over the top (OTT) content alternatives such as Netflix. Attractive new mobile use cases like linear TV services in sub-urban commuter trains or underground lines to smart phones and tablets are hard to address by the conventional high power high tower DTT which typically relies on fixed high gain rooftop antennas for proper reception. As a consequence in addition to extreme traffic growth in mobile networks, operators are facing new challenge with downlink dominant asymmetry in their mobile data networks.

This paper has introduced a novel concept of the hybrid use of the UHF broadcasting spectrum and mobile broadband using known SDL CA technique. Dynamic capability framework is used for analyzing the incentives for stakeholders, in order to help with capturing the potential benefits offered by the concept. DC concept was used to identify the antecedents, processes, and outcomes of hybrid UHF use. Based on the analysis, we have discussed a number of specific incentives that could work in the context of hybrid UHF usage. We have tried to provide help for stakeholders, including regulators, studying the future use of UHF-spectrum through discussing additional point of views and actions which may be relevant to further promote future hybrid use of UHF spectrum. As in the case of recently widely discussed LSA concept regulatory framework is the incentive in itself and particularly how incumbent's incentives are enabled.

Our study proposes options how hybrid use of UHF spectrum can become an effective means of future use of 
broadcasting band. Through dynamic capabilities view of the sharing concept this paper has tried to show how shared use of the band could lead to higher efficiency in delivering TV content to meet changing consumer needs. On one hand this could be beneficial for incumbents e.g., by preserving the spectrum, by providing additional revenues, or by lowering cost of the spectrum and, on the other hand, for the MNOs opens access to new potentially lower cost, licensed, below $1 \mathrm{GHz}$ spectrum to cope with booming data traffic. As a collaborative benefit concept opens up new business opportunities in delivering TV content using MBB network with means to introduce this flexibly.

Additionally hybrid UHF usage concept with its incentives could contribute to introduction of market-based spectrum management in the UHF broadcasting bands where market mechanisms are less developed, compared with their commercial counterparts.

In the future, dynamic capability considerations will need to be expanded to cover long-term media consumption formats, and their impact to business models (mobile operators, broadcasters, network providers/operators). On the technology side hybrid sharing concept need to be validated in field trial network in particular to research co-existence issues between LTE SDL and DVB-T2 in order to provide results to regulation.

\section{ACKNOWLEDGMENT}

This work has been performed in the Cognitive Radio to Business (CRB) and Cognitive Radio Trial Environment+ (CORE+) projects. The authors would like to acknowledge the CORE+ project consortium: VTT Technical Research Centre of Finland, University of Oulu, Centria University of Applied Sciences, Anite, Elektrobit, EXFO, Nokia Networks, PehuTec, Rugged Tooling, Finnish Defence Forces, Finnish Communications Regulatory Authority and Tekes the Finnish Funding Agency for Innovation.

\section{REFERENCES}

[1] Report ITU-R M.2243. Assessment of the global mobile broadband deployments and forecasts for International Mobile Telecommunications. 2011.

[2] Cisco white paper 2014. Cisco Visual Networking Index: Global Mobile Data Traffic Forecast Update, 2013-2018. [Online] http://www.cisco.com/c/en/us/solutions/collateral/serviceprovider/visual-networking-index-vni/white_paper_c11-520862.pdf

[3] Lewin, D., Marks. P., Nicoletti, S. 2013. Valuing the use of spectrum in the EU an independent assessment for GSMA. [online] http://plumconsulting.co.uk/pdfs/Plum_June2013_Economic_Value_of spectrum_use_in_Europe.pdf

[4] Realizing the Full Potential of Government-Held Spectrum to Spur Economic Growth, President's Council of Advisors on Science and Technology (PCAST) Report, July 2012

[5] Draft ECC Report 224. On long term vision for the UHF broadcasting band out for public consultation. July 2014

[6] 3GPP technical report TR 36.808 Evolved Universal Terrestrial Radio Access (E-UTRA); Carrier Aggregation; Base Station (BS) radio transmission and reception. June 2012

[7] Matinmikko, M., Mustonen, M., Roberson, D., Paavola, J., Höyhtyä, M., Yrjölä, S., \& Röning, J. 2014. Overview and comparison of recen spectrum sharing approaches in regulation and research. IEEE International Symposium on Dynamic Spectrum Access Networks (DYSPAN) 2014, pp.

[8] Teece, D., Pisano, M. \& Shuen, A. 1997. Dynamic capabilities and strategic management. Strategic Management Journal, Vol. 18 (7), 509 533.

[9] Matinmikko, M., Okkonen, H., Palola, M., Yrjölä, S. \& Ahokangas, P. 2014. Spectrum sharing using licensed shared access: the concept and its workflow for lte-advanced networks. IEEE Wireless Communication Magazine 21:2, 72-79.

[10] 3GPP technical specification TS 25.346 Introduction of the Multimedia Broadcast/Multicast Service (MBMS) in the Radio Access Network (RAN); Stage 2. March 2011.

[11] ECC Report 188. Future Harmonised Use of 1452-1492 MHz in CEPT. February 2013

[12] Zahra, S., Sapienza, H., Davidson, P. 2006. Entrepreneurship and dynamic capabilities: A review, model and research agenda. The Journal of Management Studies, Vol. 43 (4), 917-955.

[13] Eriksson, T. 2013. Dynamic capability of value net management in technology-based international SMEs. Dcotoral dissertation, Turku School of economics. Sarja/Series A-9:2013.

[14] Ahokangas, P., Matinmikko, M., Minervini, L., Yrjölä, S., Gonçalves, V., \& Mustonen, M. 2014 LSA Incentives for incumbent spectrum users in Licensed Shared Access (LSA): A dynamic capabilities view. European Conference on Networks and Communications (EuCNC'2014), June 2014. 